\title{
Piloting an Energy Specialist Training Program: Lessons Learned
}

\section{Dr. Sungwon S. Kim, Minnesota State University, Mankato}

Dr. Sungwon S. Kim joined the Mechanical Engineering faculty at MSU Mankato in January of 2011. He received his Ph.D. degree in Mechanical Engineering from Purdue University (2008), working in the area of synthesizing carbon nanotubes, his M.S. degree in Mechanical Engineering from Korea Advanced Institute of Science and Technology (KAIST), working in the area of designing and analyzing double spiral heat exchangers, and his B.S. degree in Mechanical Engineering from Korea University (2000).

Before joining MSU Mankato, Dr. Kim was a Visiting Assistant Professor in the School of Engineering at Purdue University, teaching courses in the thermal fluid sciences, and conducting research in nanotechnology. His research expertise and interests lie in the controlled synthesis of CNTs for thermal and biological applications. While at Purdue, he was actively involved in research sponsored by DARPA (Defense Advanced Research Projects Agency) in the development of carbon nanotube (CNT) enhanced wicks for vapor chambers (Thermal Ground Plane Program), and in enhancement of thermal interfaces using CNTs (Nano Thermal Interface Program).

Currently, his research activities are concentrated in the area of engineering education, with the purpose of promoting interest in engineering and fostering the next generation of engineers.

\section{Dr. Patrick A. Tebbe, Minnesota State University, Mankato}

Patrick Tebbe is a Professor and Chair of the Department of Mechanical and Civil Engineering at Minnesota State University in Mankato. Dr. Tebbe received the B.S., M.S., and Ph.D. degrees in Mechanical Engineering as well as the M.S. in Nuclear Engineering from the University of Missouri - Columbia. He is currently a member of the American Society for Engineering Education (ASEE), the American Society of Mechanical Engineers (ASME), the American Nuclear Society (ANS), and a student branch advisor for the American Society of Heating, Refrigerating and Air-Conditioning Engineers (ASHRAE). 


\title{
Piloting an Energy Specialist Training Program: Lessons Learned
}

\begin{abstract}
Engineering undergraduate students at the junior and senior level are exposed to many technical electives that are related to topics in energy. Traditionally, these classes have been limited to classroom instruction, however, making it difficult for students to obtain experiences that are closer to real world situations. Instructors have found it difficult as well to include outside of the classroom experiences for students.

This paper describes the implementation of a state funded project to provide an outside of the classroom opportunity for students to receive training on calculating building energy efficiency through exposure to Energy Star, Portfolio Manager and brief content on the Leadership in Energy and Environmental Design (LEED) program. Students studied the energy consumption of several buildings in the vicinity both on and off campus and calculated their respective energy efficiency ratings, which they reported back to the building facility managers. Through this training, students received real world exposure to building operations and maintenance activities. Assessment of student experiences through this project was conducted through surveys which revealed that the students had an overall positive experience, including an increased interest in the energy efficiency field. As a pilot program this project demonstrates how such a building energy efficiency training program could be continued in the future on a periodic basis, and provides directions for further expansion of this type of training program so that engineering students who are interested in continuing their careers as energy specialists have the opportunity to expand on their classroom instruction to real world applications. Lessons learned during the organization and delivery of the Energy Specialist Training Program, in addition to the lessons learned about student needs and interests in such a program and the impact to the students are presented.
\end{abstract}

\section{Background of the Program}

Buildings are a major consumer of energy in the United States. For 2009, the U.S. Energy Information Administration estimates a total of $41 \%$ of total energy consumption in the U.S. went to residential and commercial sectors whereas only $29 \%$ went to transportation. To help address issues related with building energy consumption the U.S. Green Building Council (USGBC) was formed in 1993 as a 501(c)(3) nonprofit organization. One of the group's first tasks was to develop metrics for sustainability in buildings and to identify "green buildings". This undertaking resulted in the release of the now familiar Leadership in Energy and Environmental Design (LEED) certification. However, only a portion of LEED credits are associated with energy. An alternative that offers more emphasis on energy use and conservation, particularly for smaller buildings, is the U.S. Environmental Protection Agency's Energy Star rating system. This metric benchmarks a building's energy use against itself and other similar buildings. There are several benefits including energy/cost savings and demonstration of energy awareness. Ratings are determined by entering information for buildings into the online Portfolio Manager system. However, at the current time many building 
owners, facility managers, and engineers often do not have the time and/or experience to determine the required information, input it to Portfolio Manager, and interpret the results. With access to a trained and low cost assistance program, many buildings could benefit from the Energy Star rating system. In the current economic climate this would be particularly beneficial to entities such as schools and other non-profits.

A project was proposed to pilot an Energy Specialist Training program for university students at the upper class undergraduate and graduate levels. Following the lessons of the well-known U.S. Department of Energy Industrial Assessment Centers (http://iac.rutgers.edu/) and a similar training program in Florida (http://www.kwcrackdown.com/energy-specialists/), the project would develop procedures for recruiting students, providing training on Energy Star and Portfolio Manager, facilitate the study of several regional buildings, and provide feedback to the building owners. The intent was to develop a program with demonstrated benefit to students and local businesses that could be continued and integrated as part of the educational programs at Minnesota State University, Mankato. Funding was awarded with a Low-Income Energy Training - ARRA (American Recovery and Reinvestment Act) Grant through the State of Minnesota.

\section{Student Recruitment and Training}

To assist with student recruitment the grant budget included small scholarships. Due to the lowincome restrictions on the grant, students were only able to receive a scholarship if they qualified for student financial aid. The availability of the scholarships was publicized through several programs on campus by sending information to key contacts in Mechanical Engineering, Civil Engineering, Electrical Engineering, Construction Management, Urban Studies, Manufacturing Engineering Technology, the College of Business, and the Renewable Energy Institute. The College Student Advising Center served as the collector of all applications. The Advising Center also handled all checks with the Financial Aid Office to determine applicant's low-income qualifications through the FAFSA process. The initial hope was to recruit students from several programs, including in the business area, to make more diverse groups. However, despite wide dissemination, applications were only received from mechanical and civil engineering students.

A total of nine scholarship recipients were identified. In addition, there were four undergraduates and two graduate students interested in the program who did not qualify per the low-income requirements. An In-Service course option was established so that the undergraduate students could still participate (on a non-grant supported basis) and so that the scholarship students would have a permanent record of their participation. These students were divided into two project groups.

At the start of the grant a graduate student was identified to serve as a Graduate Research Assistant in support of the grant. This turned out to be one of the most important aspects of the project. The selected student was a graduate of the mechanical engineering B.S. program and was completing a M.B.A. at the time. This student was tasked with helping to identify possible training materials, helping to assemble student notebooks, and working with the students on a one-on-one basis. 
Training materials were organized on the topics of energy benchmarking, Energy Star, and Energy Portfolio Manager. In addition, it seemed likely that students would be exposed to the State of Minnesota's B3 (Buildings, Benchmarks and Beyond) Benchmarking system so review material on this topic was also included. Ring binders of pertinent instructional material and reference information were created for each student. In addition, numerous instructional videos provided by the U.S. Department of Energy on Energy Star, and the State of Minnesota on B3, were reviewed. The most relevant were assembled into a list of assigned viewing for the students.

The graduate assistant worked with the student's schedules to determine meeting times. Students were given short presentations on topics then given assignments to complete before the next week. These assignments then led into group discussions the following week. While the graduate student ostensibly ran these meetings, at least one of the investigators attempted to be present at each meeting. Students were assigned to create Portfolio Manager accounts for themselves and to practice using the online instructional videos.

\section{Real World Training Site (Butler Square)}

Following the basic introduction to energy benchmarking it was desired to give the students some real world exposure. Through industry relations, contact was first made with EnergyPrint. This company does benchmarking and dashboard energy analysis for companies and buildings. They agreed to help provide the students with data on an existing building as a training tool.

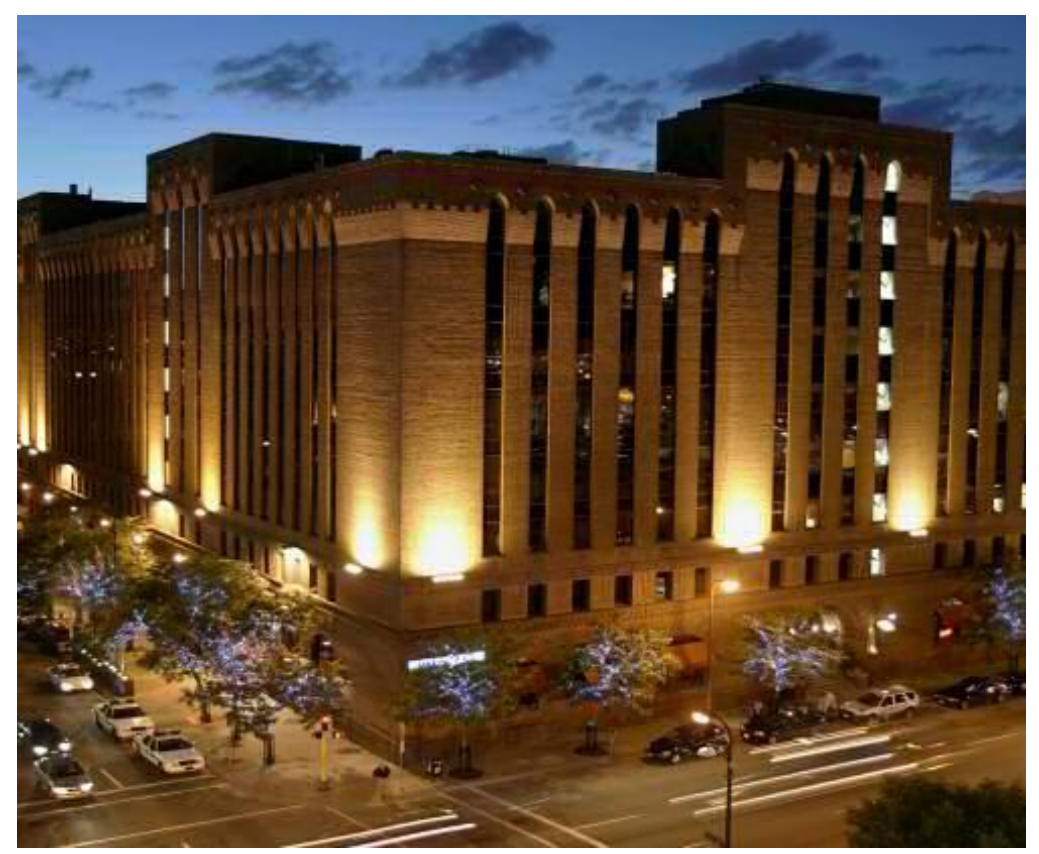

Figure 1: Butler Square building (http://www.butlersquare.com/photos.htm\#).

Through them contact was made with the Butler Square building (Figure 1), a warehouse that has been converted to an office building located in the warehouse district of Minneapolis, and its facilities management company McGough (which maintains the building's LEED 
documentation). Butler Square is the first building of its kind to receive LEED certification in the EB O\&M category (Existing Building, Operation and Maintenance). As part of energy conservation awareness efforts the building has also earned the Energy Star certification.

A tour (Figure 2) of the Butler Square building was arranged through McGough. The students were able to learn about the building, visit the boiler and facility rooms, and discuss the challenges of maintaining such a building with the facilities staff. An engineer from the Sebesta Blomberg firm was also present. This firm does energy design work for the building and suggests energy improvements. The students were able to get a good perspective from all sides through this visit.

The Butler Square building served as a test case for the students to study. Utility data was provided and the currently determined Energy Star rating. Multiple smaller student groups (2-3 students) entered data into Portfolio Manager for the Butler Square building. This allowed them to practice on a building with a known value for comparison. Students found that there was ambiguity in the space usage values and in the occupancy times that they could not verify. After making appropriate assumptions Energy Star ratings ranging from 83-88 were determined. The actual Energy Star value reported for the building is 78 . This results in a less than $10 \%$ difference. A sample Portfolio Manager screen for this analysis is shown below (Figure 3).

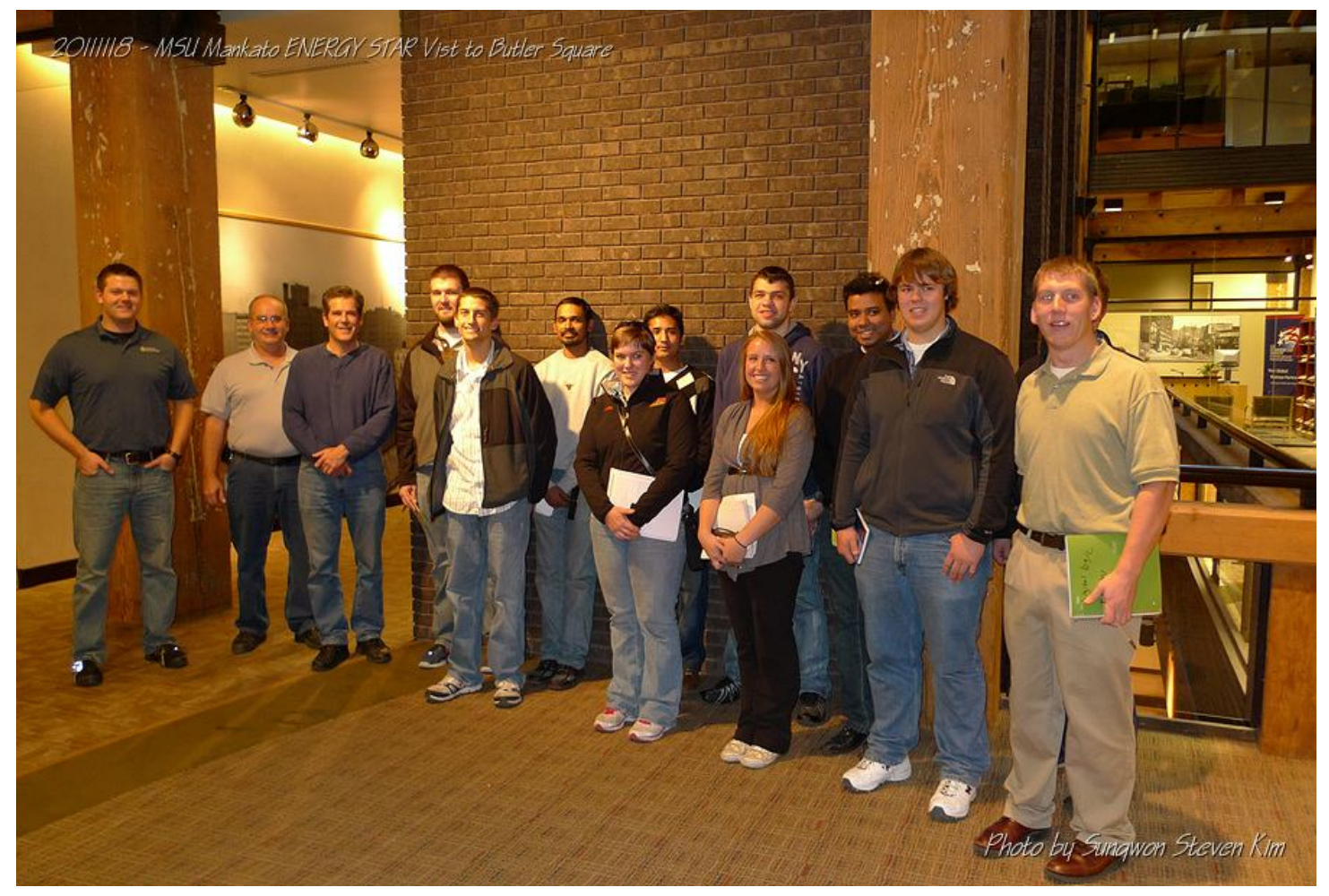

Figure 2: Photo of student visit to Butler Square building (with representatives of McGough and Sebesta Blomberg). 


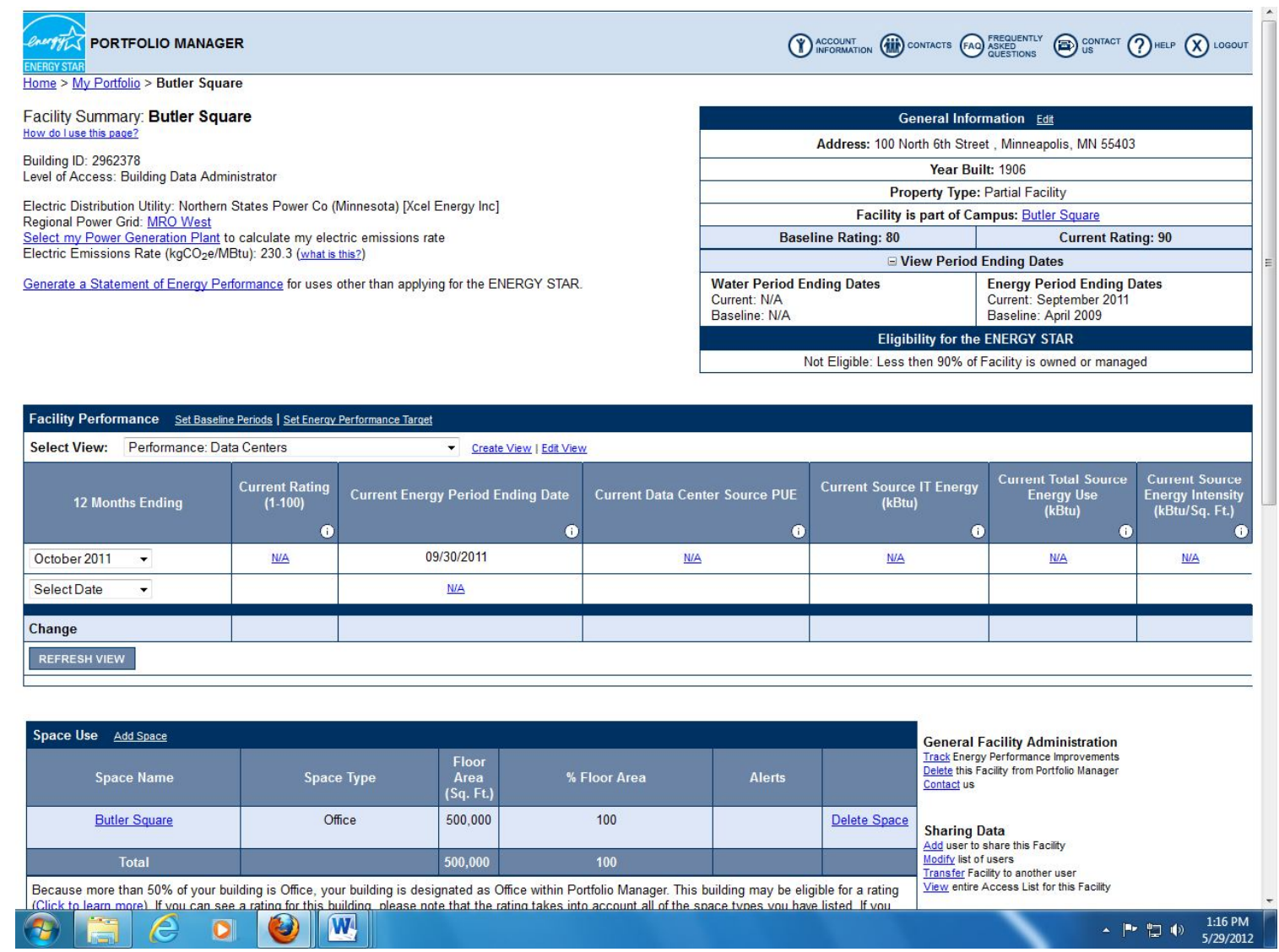

Figure 3: Example Portfolio Manager screen for Butler Square.

\section{Case Study \#1 - Student Dorm}

Following the experience with Butler Square, students were divided into two groups with each group assigned to a different building to execute a study conducted by the students. Initially the Minnesota State University Mankato Renewable Energy Laboratory building, which houses the Minnesota State University Mankato Renewable Energy Institute, was selected as a potential site. Unfortunately, the building is so new that sufficient data does not exist to make an Energy Star determination. Therefore, a new dormitory, Julia Sears Dormitory, on the MSU Mankato university campus was selected (Figure 4). This site was designed with added energy efficiency in mind and is serving as a "test site" for future dormitory development on campus.

One student group and a faculty advisor met with members of the campus Facilities Department for a tour of the new dorm and the MSU Mankato Facilities Plant. This allowed the students to see the boilers, chillers, piping, and air handling units that maintain comfort in the building. The students were also given a demonstration of the campus energy management system and their use of the B3 system. The MSU Mankato Facilities Department provided information on the energy and water usage for the dorm, as well as access to the campus blueprints for the building.

An Energy Star Portfolio was created for the new dorm. However, this building is supplied by a centralized facilities plant. This posed certain difficulties when entering information for Energy 
Star. The current energy and water metering system for the building does not correspond to the requirements of Energy Star. Values had to be determined based on a ratio of square footage. For an actual Energy Star certification a licensed engineer or architect would be required to evaluate the site and the metering method would have to be adjusted. With the assumptions made, the Energy Star rating calculated for the new dorm was 90. This would put the building in the top $10 \%$ of similar dormitories and would qualify it for an Energy Star rating. Given the recent construction of the building and emphasis on energy efficiency (heat recovery, motion sensitive lights, etc.) a high rating could be expected.

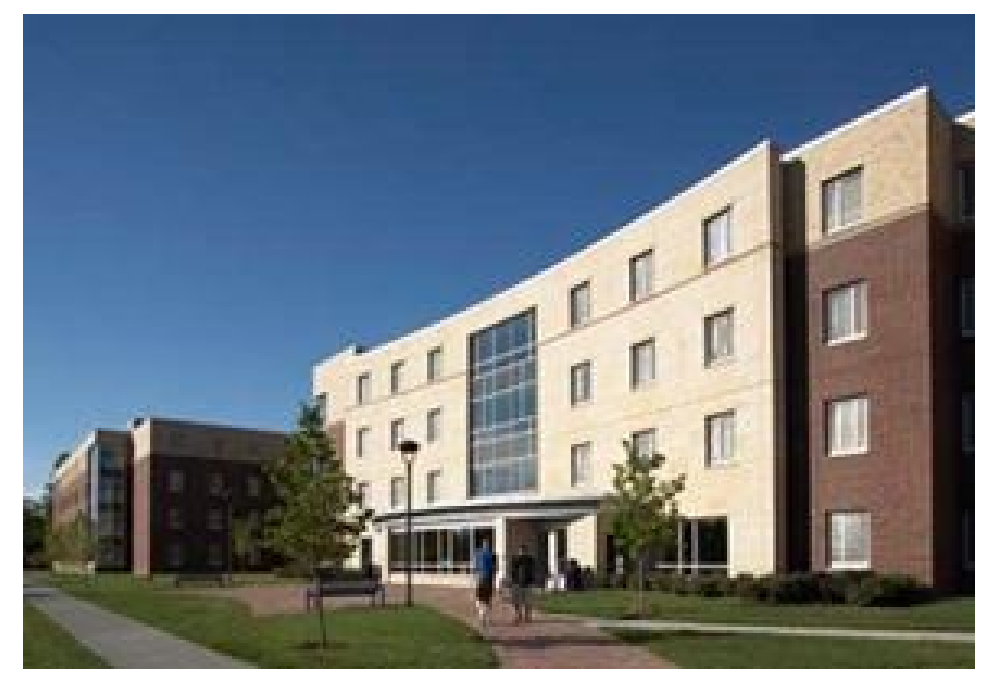

Figure 4: Julia Sears Dormitory on the Minnesota State University Mankato campus.

\section{Case Study \#2 - Local High School}

The second student group took a tour of the Le Sueur-Henderson High School building which included the boiler room, HVAC air handling units, information on new lighting systems, and an opportunity to look at the building's energy management system. Blueprints for the building were also reviewed and the current use of B3 (Buildings, Benchmarks and Beyond) Benchmarking system was discussed. Copies of the Le Sueur-Henderson High School blueprints, water usage, and gas usage were provided to the students. Contact was also provided to the district staff responsible for entering data into the B3 system for the building.

For the Le Sueur-Henderson High School two years' worth of data was entered into Portfolio Manager. Since a fairly recent remodel of the building had occurred it was possible to compare, or benchmark, values from before and after the remodel. Conservative assumptions were made concerning the occupancy of the building. For before remodel (circa 2008) a rating of 61 was determined. For after remodel (circa 2011) a rating of 80 was determined. This shows a marked improvement in building performance following the remodel. The current value of 80 , being greater than 75, would qualify the building for an Energy Star certification. The first step toward 
this would be for the school to hire a licensed engineer or architect to assess the validity of all values and assumptions, and to certify the rating.

The Le Sueur-Henderson High School group arranged a final meeting at the high school with the Director of Buildings and Grounds and the Superintendent. Based on this presentation the district is considering the option of pursing Energy Star certification through their district architect. Through Energy Star certification, it is expected that the Le Sueur-Henderson High School will be able to increase awareness of energy related issues in the students and the local population, and to lay the groundwork for further cost savings with respect to building energy maintenance costs.

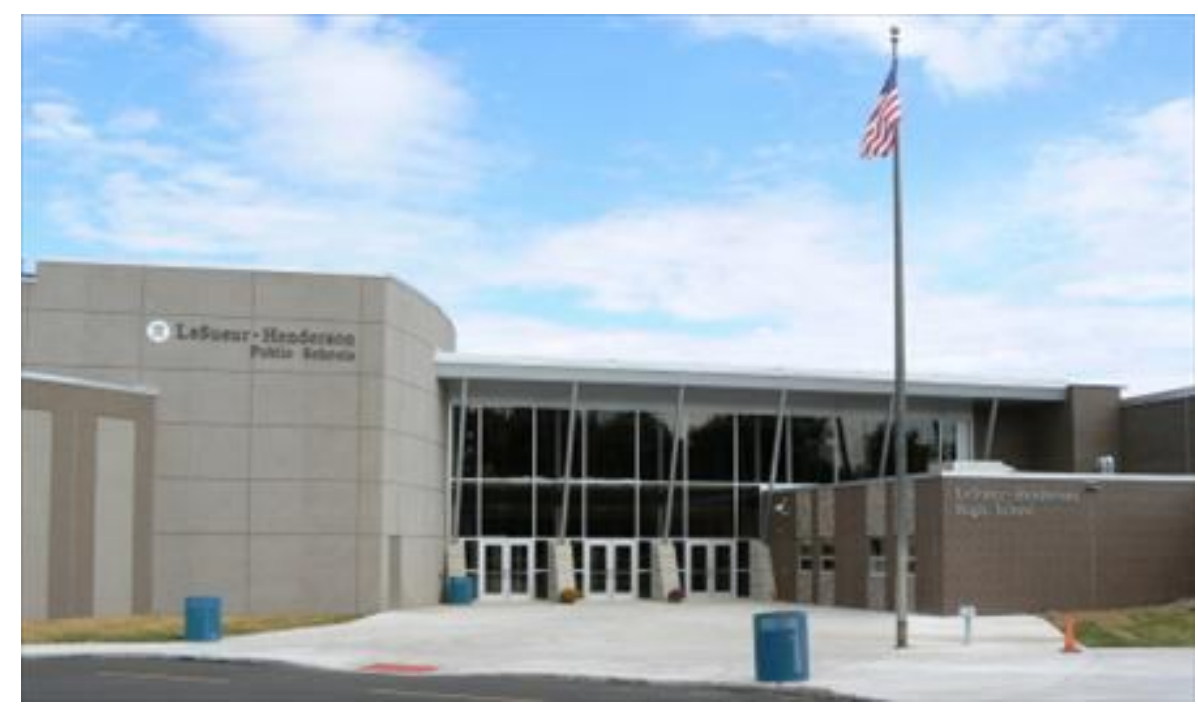

Figure 5: Le Sueur-Henderson High School (http://isd2397hsms.sharpschool.net/home).

\section{Student Assessment of the Experience}

Near the conclusion of the grant the scholarship recipients were given a short survey in order to help assess the program and suggest improvements for future, similar, activities. Out of the nine scholarship recipients, six returned full surveys. The results are summarized in Table 1.

Student responses indicated that aspects related to the real world practice of engineering were the most beneficial. This included working in teams and making real world presentations. Talking with the building personnel, learning about Energy Star, and being exposed to the LEED process were also stated as positives. Being able to see how buildings can be operated and designed more efficiently was a positive aspect. However, the students desired additional information on why certain steps are done, particularly from the design point of view. 


\section{$\underline{\text { Table 1: Student Assessment Results }}$}

1. Rate the overall experience of the training program.
1
2
3
4
5

$\begin{array}{llll}\text { Negative } & \text { Weak } & \text { Neutral } & \text { Positive Positive }\end{array}$

The average student rating for this question was 4.3 indicating a positive overall experience.

2. Rate the amount of knowledge or experience you felt you gained in comparison to an equivalent amount of time in the classroom.
1
2
3
4
5

$\begin{array}{llll}\text { Much less } & \text { Less } & \text { Same } & \text { More }\end{array}$

The average student rating for this question was 4.0 indicating that the grant's activities appeared to impart more knowledge than a typical classroom experience.

3. How has this experience affected your interest in the energy field as a profession?
1
2
3
4
5

Decreased interest Somewhat less Neutral Somewhat more Greatly increased

The average student rating for this question was 4.3 indicating that student interest in this field was increased because of the experience.

4. How likely are you to recommend this (or a similar program) to another student?
1
2
3
4
5

$\begin{array}{llll}\text { Very unlikely } & \text { Not likely } & \text { Neutral } & \text { Likely }\end{array}$

The average student rating for this question was 4.5 indicating a high likelihood that students would recommend this, or a similar, program to fellow students. 


\section{Discussion and Conclusions}

Student surveys indicated that students had a positive experience, were provided a valuable learning experience, had an increased interest in the energy efficiency field, and would recommend the program to fellow students. Junior level students who participated are continuing to take courses related with the field of energy. It is expected that all students who took part in the program will be able to exhibit basic knowledge of building energy usage calculation, so that they may attempt to pursue further career opportunities in related fields. Response from industry and client buildings was very positive. The experience with the Local High School demonstrates that there is interest in continuing/expanding the program at the high school level. One student received an industry job shadowing experience through the program and the graduate research assistant who was employed on the grant has now accepted a full time position with a company dealing with energy generation.

Overall the project can be judged a success. As a pilot program it demonstrated how such a training program can be operated. However, it is uncertain if such a program could be continued without some form of minimal support (such as for scholarships and graduate assistants). The next phase of development would therefore be seeking continuation funding, perhaps from industry.

The authors would like to acknowledge the support provided by the U.S. Department of Energy and the Minnesota Department of Commerce (Agreement \#B55709) that made this work possible. 